\title{
ASSESSMENT OF THE LEVEL OF KNOWLEDGE AND PRACTICE TOWARDS ROAD TRAFFIC SAFETY AMONG MALE ADOLESCENTS IN URBAN SLUMS OF DELHI
}

\author{
Prakash Singh 1, Pushpanjali Swain ${ }^{2}$ \\ ${ }^{1}$ Master's in public health, Centre for Public Health, Panjab University, Chandigarh, India \\ 2 Professor and Head, Department of Statistics and Demography, NIHFW, New Delhi, India
}

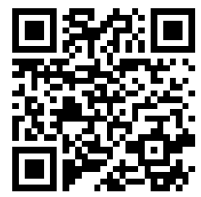

DOI: https://doi.org/10.29121/granthaalayah.v8.i5.2020.109

Article Type: Research Article

Article Citation: Prakash Singh, and Pushpanjali Swain. (2020).

ASSESSMENT OF THE LEVEL OF KNOWLEDGE AND PRACTICE TOWARDS ROAD TRAFFIC SAFETY AMONG MALE ADOLESCENTS IN URBAN SLUMS OF DELHI. International Journal of Research GRANTHAALAYAH, 8(5), 165-172. https://doi.org/10.29121/granthaa layah.v8.i5.2020.109

Received Date: 16 May 2020

Accepted Date: 31 May 2020

Keywords:

Adolescents

Road Traffic Safety

\section{ABSTRACT}

Background: Globally, road traffic injuries are leading cause of death among the adolescents. Sustainable development goal 3.6 suggests reducing deaths and injuries due to road traffic accidents. The risk of vehicular accidents increases further for the adolescents when they drink and drive. Hence it is pertinent to assess the knowledge and practice regarding road traffic safety, alcohol consumption practices among male adolescents of urban slums of Delhi. The main objective of the study was to assess the level of knowledge and practice regarding road traffic safety, among the male adolescents.

Methods: A cross sectional study was carried out among 100 male adolescents from urban slums of Delhi. Data was collected using semistructured, self-administered interview schedule. The collected data was entered using Microsoft Excel 2007 and was analyzed using IBM SPSS statistics 20. Chi-square test was applied and level of significance was kept at $p$-value of $<0.05$. The study period was from 11 th June to 31 st July.

Results: Among the study subjects, $44.0 \%$ had the adequate knowledge regarding road traffic safety. Among all the respondents who knew driving 92.9\% participants drive vehicles without license including both juvenile and $>18$ years of age. There was no significant relationship found between knowledge regarding road traffic safety and practice. There was good knowledge found regarding harmful effects of tobacco and alcohol consumption among the participants.

Conclusions: In the study, it was revealed that mere knowledge regarding road traffic safety important however; there was large gap between knowledge and practice. The implementation of road traffic rules is needed and mass media should be strengthened to follow road traffic rules by adolescents.

\section{INTRODUCTION}

Around 1.2 billion people, or 1 in 6 of the world's population, are adolescents aged 10 to 19.[16] In India it represents a substantial proportion of India's population of 243 million (22\%).[21] They are a rich human resource and an important part of the growth process. Globally, road traffic injuries are leading cause of death among the

(C) 2020 The Author(s). This is an open access article distributed under the terms of the Creative Commons Attribution License, which permits unrestricted use, distribution, and reproduction in any medium, provided the original author and source are credited. 
adolescents. Every year there are 1,05,725 deaths occur out of which $84 \%$ are in the age group of $12-19$ year.[9] The Global status report on road safety 2013 indicates that worldwide the total number of road traffic deaths remain unacceptably high at 1.24 million per year. Road traffic injuries are the leading cause of death among young people aged 15-29 years.[10] According to a study, India contribute $27 \%$ of worldwide road traffic accidents positioned second in number 9 . India is the second largest road network in the world with expansion of 3 million KM of roads in which $60 \%$ are paved. These roads make a vital contribution to India's economy. On the whole, the facilities for the road users are not up to the marks, leading to a high toll of the death victims. Recently, there is a growing concern over the road crash problem.[11]

According to Swami H M et al. (2006), conducted a study on "Road safety awareness and practice among school children of Chandigarh". The study revealed that $40 \%$ of students lacked correct knowledge of traffic safety rules. In particular, knowledge of correct speed limit was lacking in $67.3 \%$ of the respondents. Girls were more aware of traffic rules to be followed at traffic lights $(63 \%)$ and while crossing zebra lines $(41.2 \%)$, whereas boys were more versed with rules for pedestrians (49.8\%). Around 60\% of school children had correct knowledge of risk factors.[2] A study by Kalbandkeri R. Lakshmi et al. (2018), assessed the "Knowledge and practice of road safety measures among undergraduate medical students" of M. R. Medical College, Kalaburagi, which revealed that out of the 310 students $54.19 \%$ were males and $45.81 \%$ were females. $90.9 \%$ of the participants had driving license, $32.1 \%$ of the students had taken training for driving the car and $66 \%$ of the students did not wear helmet. Female students had high knowledge of the road safety measures when compared to male students. The overall knowledge of road safety measures was high among the study participants.[3] According to Singh Jyotsna (2015), conducted study on "Road accidents top reason for adolescent deaths: WHO". Road traffic injuries are the number one cause of adolescent deaths globally following illness and disability and it was seen that boys are three times more affected that of girls. The report says increasing access to reliable and safe public transport can reduce road traffic injuries among adolescents. Road safety regulations (alcohol and speed limits) and establishing safe pedestrian areas around schools can reduce risks. It also recommends graduated licensing schemes, in which a full driver's license is given after many steps. Till then, a person has to follow certain restrictions while driving.[14] Ranjan Prakash et al. (2018), did a cross sectional study to assess the "Knowledge, attitude and practice towards road traffic safety among adolescent students" of a selected Pre-University college in Raichur city, the study revealed that globally, road traffic injuries are estimated to be the leading cause of death among young people aged 15-29 years, and second for 10-14 years and 20-24 years age groups whereas high speed found out to be the common reason. Results: Mean age of the participants was $16.68 \pm 0.75 .196$ participants (52.8\%) had adequate knowledge on the road safety rules and regulations. Only 25 participants $(7.7 \%)$ were driving with a valid driving license. Knowledge adequacy about road safety rules and regulations had statistically significant association with age and gender. Conclusions: Mere knowledge does not necessarily translate into improved traffic behavior as was seen in this study.[24] According to Ratna V.K Harish et al. (2018), conducted study on "Awareness and behavior patterns regarding road safety measures among undergraduate students". The study revealed that in total, 200 dental students were studied, ranging from $1^{\text {st }}$ to final year of age 17-27 years; the mean age being 21.67 and standard deviation of 3.170 . The awareness measures among the study participants were satisfactory but interpretation of traffic signs was pooronly $30.5 \%$ interpreted gap-in-median correct. The behavioral patterns among students are not satisfactory-only $74 \%$ of students wear helmet while riding, only $81.5 \%$ wear seat belts and $23.5 \%$ don't follow lane rules while driving.[5]

Although these studies discuss about the adolescent's knowledge and practice of on road safety, however, it is pertinent to understand the knowledge and practice of road safety among adolescent living in slum. As country is progressing in economic front, to improve the level of subsistence the slum dwellers are also depending on two wheels motor vehicle mostly.

Objective: To assess the level of knowledge and practice towards Road traffic safety among the male adolescents residing in urban slum areas and their alcohol consumption.

\section{METHODOLOGY}

A cross sectional study was carried out among 100 male adolescents from urban slums of Delhi. Data was collected using semi-structured, self-administered interview schedule. Data was collected using convenient 
sampling technique. A written consent form was also taken from the participants. The collected data was entered using Microsoft Excel 2007 and was analyzed using IBM SPSS statistics 20. Chi-square test was applied and level of significance was kept at $\mathrm{P}$-value of $<0.05$. The study period was from $11^{\text {th }}$ June to $31^{\text {st }}$ July. There were no funding sources.

\section{FINDINGS}

Table 1: Socio demographic detail of the participants.

\begin{tabular}{|c|c|c|}
\hline Characteristics & Category & Numbers of respondents $(\mathrm{N}=100)(\%)$ \\
\hline \multirow{3}{*}{ Age } & $12-15$ & $(18.0)$ \\
\hline & $15-18$ & $(28.0)$ \\
\hline & 18-19 & $(54.0)$ \\
\hline \multirow{5}{*}{ Educational status } & Illiterate & $(10.0)$ \\
\hline & Primary & $(6.0)$ \\
\hline & Elementary & $(26.0)$ \\
\hline & Secondary & $(32.0)$ \\
\hline & Senior-secondary & $(26.0)$ \\
\hline \multirow{3}{*}{ Father's qualification } & Illiterate & $(22.0)$ \\
\hline & Primary & $(34.0)$ \\
\hline & Secondary & $(44.0)$ \\
\hline \multirow{3}{*}{ Mother's qualification } & Illiterate & $(46.0)$ \\
\hline & Primary & $(26.0)$ \\
\hline & Secondary & $(18.0)$ \\
\hline \multirow{4}{*}{ Father's occupation } & Unemployed & $(8.0)$ \\
\hline & Private employee & $(64.0)$ \\
\hline & Govt. employee & $(18.0)$ \\
\hline & Daily wages & $(10.0)$ \\
\hline \multirow{3}{*}{ Mother's occupation } & House-wife & $(40.0)$ \\
\hline & Private employee & $(50.0)$ \\
\hline & Daily wages & $(10.0)$ \\
\hline \multirow{3}{*}{ Monthly income } & $5000-10,000$ & $(18.0)$ \\
\hline & $10,000-20,000$ & $(58.0)$ \\
\hline & $>20,000$ & $(24.0)$ \\
\hline \multirow[b]{2}{*}{ Family type } & Nuclear & $(92.0)$ \\
\hline & Joint & $(8.0)$ \\
\hline \multirow{3}{*}{ No. of family members } & $2-4$ & $(36.0)$ \\
\hline & $5-10$ & $(60.0)$ \\
\hline & $>10$ & $(4.0)$ \\
\hline \multirow[b]{2}{*}{ Religion } & Hindu & $(94.0)$ \\
\hline & Muslim & $(6.0)$ \\
\hline
\end{tabular}

The study included 100 participants (males). The age of participants ranged from 12 to 19 years.

Table 2: Knowledge regarding road traffic safety rules by adolescent males

\begin{tabular}{|l|c|}
\hline Knowledge regarding road traffic safety & No. with correct response (N=100) (\%) \\
\hline Age to get driving license & $(84.0)$ \\
\hline Normal speed for driving two-wheeler in city & $(46.0)$ \\
\hline Normal speed for driving four-wheeler in city & $(48.0)$ \\
\hline Permissible blood alcohol level limit for driving in India (in \%) & $(46.0)$ \\
\hline Is it compulsory to wear helmet while riding a two-wheeler & $(100.0)$ \\
\hline
\end{tabular}


Assessment of The Level of Knowledge and Practice Towards Road Traffic Safety Among Male Adolescents in Urban Slums of Delhi

\begin{tabular}{|l|c|}
\hline Is it compulsory to wear seat belt while driving a four-wheeler & $(100.0)$ \\
\hline From where do you overtake vehicles & $(26.0)$ \\
\hline On which side of road, you must walk to reduce accidents & $(18.0)$ \\
\hline Maximum penalty for driving without driving license & $(50.0)$ \\
\hline Road signs (4 out of 8 signs were correct) & $(8.0)$ \\
\hline
\end{tabular}

Normal speed for driving two-wheeler in city is $40 \mathrm{kmph}$ this was known by only (46.0\%) and for four-wheeler is $50 \mathrm{kmph}$ and was only known by $(48.0 \%)$ participants. Only $(46.0 \%)$ participants knew that permissible blood alcohol limit for driving in India is 30\%. (26.0\%) participants were having the knowledge that we should overtake the vehicle from right. (18.0\%) participants were having the knowledge that to avoid road accidents we must walk on right side of the road (facing towards moving traffic). Maximum penalty for driving without driver's license was known by only (50.0\%) participants. Only (2.0\%) participant knew all the 8 road signs. Only (8.0\%) participants were having the knowledge of (4 out of 8 signs). Among all the participants, $(82.0 \%)$ had the knowledge of driving. According to motor vehicle act (MVA) the minimum age to get driving license is 18 years. This was known by ( $84.0 \%)$ participants. All the participants knew that it is compulsory to wear helmet while riding/travelling a two-wheeler. All the participants knew that it is compulsory to wear seat belt while driving/travelling in a four-wheeler. (Table No. 2)

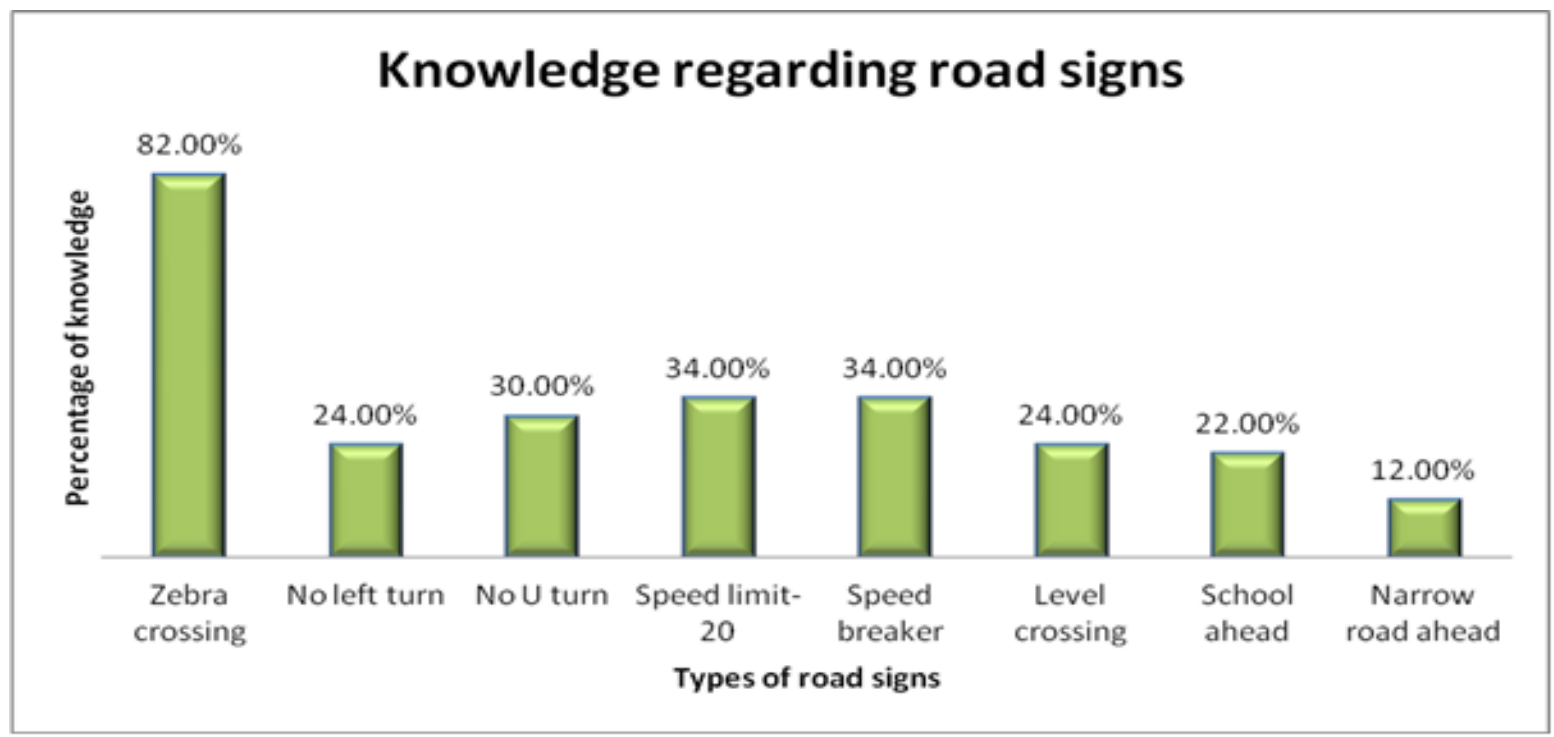

Figure 1: Knowledge regarding different road signs.

Among the participants of the study, majority had the knowledge regarding zebra crossing (82.0\%) as the road signs. Other road signs such as speed limit-20 and speed breaker, about one-third (34.0\%) participants knew about signs. One fourth $(24.0 \%)$ participants knew the sign of no left turn and level crossing sign. No U turn sign was known by $(30.0 \%)$ of participants. One-fifth $(22.0 \%)$ participants knew about school ahead sign. The narrow road ahead sign was known by only (12.0\%) of the participants. (Figure No. 1)

Table 3: Practice regarding road safety among all the participants.

\begin{tabular}{|l|c|}
\hline Practice regarding road safety of all participants & No. of respondents $(\mathrm{N}=100)(\%)$ \\
\hline Use zebra crossing while crossing roads & $(52.0)$ \\
\hline Obey road signs and symbols & $(62.0)$ \\
\hline Wear helmet while riding/travelling on two-wheeler & $(50.0)$ \\
\hline
\end{tabular}

Among all the participants only (52.0\%) used zebra crossing while crossing roads. Even though it is compulsory to wear helmet and seat belt while driving/travelling with two-wheeler. Only (50.0\%) wear helmet travelling/driving. (Table No. 3) 
Table 4: Practice regarding road traffic safety among the participants who drive vehicles.

\begin{tabular}{|l|c|}
\hline Practice regarding road traffic safety of respondents who drive vehicles & Number of respondents (N=84) (\%) \\
\hline Drive vehicles without license & $(92.9)$ \\
\hline Use mobile phones while driving & $(64.3)$ \\
\hline Ever been held by traffic police & $(66.1)$ \\
\hline $\begin{array}{l}\text { Stop Vehicles for pedestrians to cross even with no traffic signal or traffic } \\
\text { police around }\end{array}$ & $(66.7)$ \\
\hline Use indicator & $(61.9)$ \\
\hline Drink and drive & $(80.9)$ \\
\hline Drive vehicles without parent's knowledge & $(45.2)$ \\
\hline Practice juvenile driving & \\
\hline
\end{tabular}

Among all the participants (84.0\%) knew driving and drive vehicles. Among those participants who drive vehicles (92.9\%) drive vehicles without license. (64.3\%) participants used mobile phones while driving. Only $(66.7 \%)$ used indicators while driving. Among the participants who drive vehicles $(61.9 \%)$ had the habit of drink and then drive vehicles. (80.9\%) adolescents drive vehicles without their parents' knowledge. Only (66.7\%) stop vehicles for pedestrians to cross even with no traffic signal or traffic police around. (38.1\%) were held by traffic police for one or more reasons. Among all the participants who drive (45.2\%) were juvenile (less than 18 years of age) drivers. (Table No. 4)

\section{Encounter with traffic police of participants who drive vehicles}

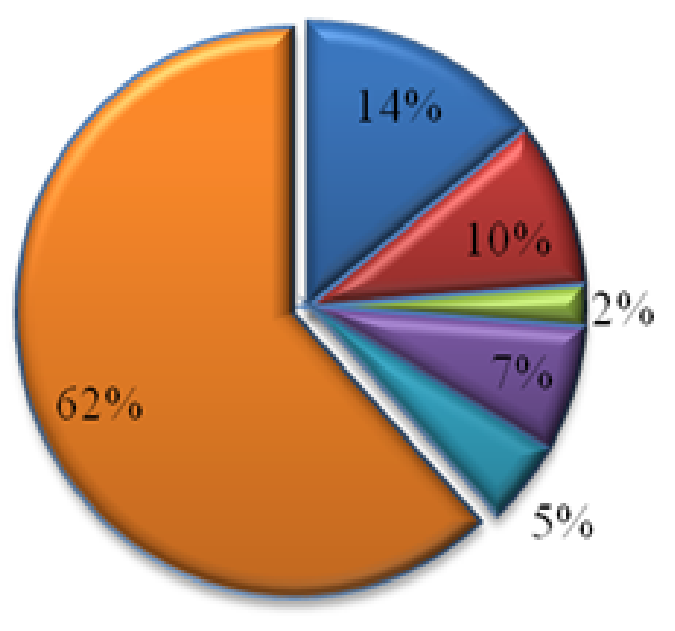

回 No helmet

No license

回 Rash driving

四ripple riding

areaking red lights

呩ot caught

Figure 2: Encounter with traffic police of participants who drive vehicles.

Among all the participants who drive vehicles (N=84) 62.0\% participants were never caught in spite of breaking rules. (Figure No. 2)

Table 5: Participants having valid driving license who were above 18 years of age.

\begin{tabular}{|l|c|}
\hline Characteristic & No. of respondents (N=54) (\%) \\
\hline Having driving license & $(11.1)$ \\
\hline No driving license & $(88.8)$ \\
\hline
\end{tabular}

Among the study participants 54 participants were above 18 years of age only. Among them (11.1\%) were having a valid driving license. (Table No. 5) 
Assessment of The Level of Knowledge and Practice Towards Road Traffic Safety Among Male Adolescents in Urban Slums of Delhi

Table 6: Relationship between knowledge adequacy and practice regarding road traffic safety among the participants who drive vehicles.

\begin{tabular}{|l|c|c|c|c|}
\hline Practices & $\begin{array}{c}\text { Adequate knowledge } \\
(\%)\end{array}$ & $\begin{array}{c}\text { Inadequate knowledge } \\
(\%)\end{array}$ & $\begin{array}{c}\text { Total (N=84) } \\
(\%)\end{array}$ & $\begin{array}{c}\text { P } \\
\text { value }\end{array}$ \\
\hline Drive vehicles without license & $(48.7)$ & $(51.2)$ & $(100)$ \\
\hline Yes & $(66.6)$ & $(33.3)$ & $(100)$ & \\
\hline No while & & & \\
\hline $\begin{array}{l}\text { Use mobile phones } \\
\text { driving }\end{array}$ & $(33.3)$ & $(66.6)$ & $(100)$ \\
\hline Yes & $(80.0)$ & $(20.0)$ & $(100)$ & \\
\hline No & & & $(100)$ & 0.035 \\
\hline Ever been held by traffic police & $(43.7)$ & $(56.2)$ & $(308$ \\
\hline Yes & & & \\
\end{tabular}

Between overall knowledge adequacy regarding road traffic safety and practice among the participants who drive vehicles was compared. The participants who drive vehicles had significant association with road traffic safety practice. (Table No. 6) The difference in knowledge and practice of participants who use mobile phones while driving was found to be statistically significant ( $\mathrm{P}$ value 0.035 ). There was also a significant association between the knowledge and practice of participants who stop vehicles for pedestrians to cross even with no traffic light or traffic police around ( $\mathrm{P}$ value 0.024). The significant association was also found between the adequate knowledge and practice of participants who used indicators while driving ( $\mathrm{P}$ value 0.031 ).

Knowledge adequacy: Knowledge and practice questions related to road traffic safety, 11 questions were asked to assess the knowledge of road traffic safety and 13 questions were asked related to road traffic practice. The knowledge level regarding road traffic safety was scored in two categories adequate and inadequate. A total of 7 knowledge question were taken and (0-3) was considered knowledge inadequate and (4-5) was considered knowledge adequate.

There was significant knowledge practice gap among all the participants regarding road traffic safety. There was a relationship found between knowledge and practice regarding road traffic safety of the participants who drive vehicles. The significant association was found between use of mobile phones while driving (P value 0.035), Stop vehicles for pedestrians to cross even with no traffic signal or traffic police around (P value 0.024) and using indicator while driving ( $\mathrm{P}$ value 0.031 ) with the practice. This was in contrast to the study conducted by Prakash Ranjan et al. in Raichur among adolescent students of a selected Pre-University college (2018).[4]

The significance difference was found between practice and age of all the participants. The significant association was found between using zebra crossing while crossing roads ( $\mathrm{P}$ value 0.05 ) and obeying road signs and symbols ( $\mathrm{P}$ value 0.02). The relationship between age and practice of the participants who drive vehicles was not significant. The significant relationship was found only in between two variables, ever been held by traffic police (P value 0.042 ) and drink and drive ( $P$ value 0.009 ). The findings of the study were similar to the study conducted by Harish V. K. Ratna et al. Awareness and behavior patterns regarding road safety measures among undergraduate students (2018). ${ }^{5}$

\section{CONCLUSION AND RECOMMENDATIONS}

The awareness regarding road traffic safety among the participants was inadequate like the interpretation of road signs was poor-only (12.0\%) participants could identify the narrow road ahead correct. Only (44.0\%) had the adequate knowledge and (56.0\%) had the inadequate knowledge regarding road traffic safety. The practice of regarding road traffic safety of all the participants was average only (52.0\%) participants used zebra crossing to cross roads and only (50.0\%) participants had the habit of wearing helmet while travelling/riding on a two-wheeler. Only (11.1\%) participants above 18 years of age were having valid driving license. $92.9 \%$ participants drive vehicles without license out of which (45.2\%) were the juvenile drivers. There were $(45.2 \%)$ juvenile drivers and those who were having the habit of drink and drive (61.9\%). This concludes that they were exposed to road traffic accidents. 
The relationship between knowledge and practice was not found to be significant. Mere knowledge regarding road traffic safety is not important. Those having the knowledge didn't practice the same.

Traffic safety is an essential part of public health and accidents preventions. Careful and adequate interventions need to be introduced and educated among adolescents to prevent traffic accidents. Road traffic safety can be ensured through awareness programs towards road safety measures through signboards, posters and mass media especially for the adolescents on regular basis to reduce the burden of road traffic accidents. Slums are the most neglected area; governments should engage in different programs to create awareness in these aspects. Strict enforcement of laws and periodic organization of traffic awareness campaigns in slum areas are essential for checking out risky practices in driving.

\section{Limitations}

- Sample size was small due to time constrain.

- Only male population was targeted.

- Study cannot be generalized due to small sample size.

\section{SOURCES OF FUNDING}

None.

\section{CONFLICT OF INTEREST}

None.

\section{ACKNOWLEDGMENT}

None.

\section{REFERENCES}

[1] Adolescence an age of opportunity, UNICEF [Last accessed on 2019 June 4]

[2] Swami, H M \& Puri, S \& Bhatia, Vikas. (2006). Road Safety Awareness and Practices among School Children of Chandigarh. Indian Journal of Community Medicine. p.31.

[3] Lakshmi R. Kalbandkeri, Boramma G., Shreeshail Ghooli, (2018), A study to assess the knowledge and practice of road safety measures among undergraduate medical students of M. R. Medical College, Kalaburagi,

[4] Ranjan P., Din \& A. Fahim, M \& C. Kirte, Rahul. (2018). A cross sectional study to assess the knowledge, attitude and practice towards road traffic safety among adolescent students of a selected Pre-University college in Raichur city. International Journal of Community Medicine and Public Health. 10.18203/23946040. ijcmph20182175.

[5] Harish V. K. Ratna, Rajesh S. S., Jayaram A., Rajanna M. S., Venkatesh P. Krishna Iyengar, (2018) Awareness and behaviour patterns regarding road safety measures among undergraduate students [Last accessed on 2019 June 4]

[6] World health organisation, [cited at: https://www.who.int/about/who-we-are/constitution] [Last accessed on 2019 June 5]

[7] Adolescents: health risks and solutions, by WHO [Cited at: https://www.who.int/news-room/factsheets/detail/adolescents-health-risks-and-solutions] [Last accessed on 2019 June 5]

[8] Adolescent Health Awareness Life Skill \& adolescent Health Education for School children or class 9th to 12th (age of 13 to 19 year), The Divine light, Cited at- http://www.thedivinelight.in/adolescent-healthawareness/ [Last accessed on 2019 June 5]

[9] Kohli G., Kodi M., Sethi M., Road accidents among adolescent, Journal of Asia pacific studies, December 2013, Vol 3 No 2, 245-259 
Assessment of The Level of Knowledge and Practice Towards Road Traffic Safety Among Male Adolescents in Urban Slums of Delhi

[10] National health portal, [ Cited at: https://www.nhp.gov.in/road-traffic-accidents_pg] Last accessed on 2019 June 6]

[11] R. Sengupta, November 21, 2018, Traffic signs and road safety.

[12] World health organisation, [Cited at: http://apps.who.int/adolescent/seconddecade/section/section_2/level2_2.php] [Last accessed on: 2019 June 6]

[13] Michael Westwood, MB ChB MRCP(UK) FRCPC Jorge Pinzon, MDFRCPC, Pediatrics \& Child Health, Volume 13, Issue 1, January 2008, Pages 31-36, Adolescent male health.

[14] Singh J., 17th August, 2015, Road accidents top reason for adolescent deaths: WHO [Cited at: https://www.downtoearth.org.in/news/road-accidents-top-reason-for-adolescent-deaths-who-44353] [Last accessed on: 2019 June 6]

[15] Csikszentmihalyi M., June 14th, 2019, Adolescence, [Cited at: https://www.britannica.com/science/adolescence] [Last accessed on 2019 June 6]

[16] Coming of age: adolescent health, World health organization, [Cited at: https://www.who.int/healthtopics/adolescents/coming-of-age-adolescent-health] [last accessed on 2019 June 6]

[17] Adolescent health, World health organization, [Cited at: http://www.searo.who.int/topics/adolescent_health/en/] [Last accessed on 2019 June 6]

[18] Adolescent health and development, World health organization [Cited at: http://www.searo.who.int/entity/child_adolescent/topics/adolescent_health/en/] [Last accessed on 2019 June 7]

[19] Recognizing adolescence, World health organization [Cited at: http://apps.who.int/adolescent/seconddecade/section2/page1/recognizing-adolescence.html] [Last accessed o 2019 June 7]

[20] What about boys? World health organization [Cited at: https://apps.who.int/iris/bitstream/handle/10665/66487/WHO_FCH_CAH_00.7.pdf;jsessionid=A5197E4 D7C1339B38B4B1D98FE835481?sequence=] [Last accessed on 2019 June 7]

[21] Adolescence an age of opportunity, UNICEF, [Cited at: http://unicef.in/PressReleases/87/Adolescence-AnAge-of-Opportunity] [Last accessed on 2019 June 7]

[22] Road safety-alcohol, World health organization, [Cited on: https://www.who.int/violence_injury_prevention/publications/road_traffic/world_report/alcohol_en.pdf] [Last accessed on 2019 June 7]

[23] Be healthy, World Health Organisation, [Cited at: https://www.who.int/behealthy] [Last accessed on 2019 June 8]

[24] Tobacco, World Health Organisation, [Cited at: https://www.who.int/health-topics/tobacco] [Last accessed on 2019 June 8]

[25] Kalbandkeri L.R., Boramma G., Ghooli S., (2018) A study to assess the knowledge and practice of road safety measures among undergraduate medical students of M. R. Medical College, Kalaburagi.p.14

[26] Sustainable Development Goal, [Cited at: https://sustainabledevelopment.un.org/sdg3] [Last accessed on 2019 June 8] 